\title{
Swarms of swift scavengers: ecological role of marine intertidal hermit crabs in California
}

\author{
Mark E. Laidre $^{1 *}$ and Alison L. Greggor ${ }^{1}$ \\ ${ }^{1}$ Department of Integrative Biology, University of California, Berkeley
}

Running title: Swarms of swift scavengers

Word count

Abstract: 241

Main text (including references): 5,475

With 2 Tables and 4 Figures

Electronic Supplementary Material (4 Supplementary Figures)

*Corresponding author address:

Department of Biological Sciences

Dartmouth College

The Class of 1978 Life Sciences Center

78 College Street

Hanover, NH 03755

Phone: +1 (609) 751-8041, Fax: +1 (603) 646-1347

Email: mark.laidre@dartmouth.edu 


\section{Abstract}

2 While marine hermit crabs are well known for being omnivorous filter feeders, less is

3 known about the role they may play as active carrion scavengers in intertidal ecosystems.

4 Prior studies have revealed that intertidal hermit crabs can be attracted to chemical cues

5 from predated gastropods. Yet their attraction is usually assumed to be driven primarily

6 by the availability of new shells rather than by food. We conducted field experiments to

7 assess hermit crabs' potential role as generalist carrion scavengers on the California

8 coast, examining their speed of attraction and the size of the aggregations they formed in

9 response to chemical cues from freshly smashed gastropods and mussels, both of which

10 indicated available carrion. Compared to all other marine species, hermit crabs (including

11 Pagurus samuelis, Pagurus hirsutiusculus, and Pagurus granosimanus) were the fastest

12 to arrive at the provisioning sites, and they also dominated the provisioning sites, forming

13 aggregations of up to 20 individuals, which outcompeted all other scavengers for carrion.

14 Notably, hermit crabs arrived equally quickly for both smashed gastropod and mussel,

15 even though the latter does not offer suitable shells for hermit crabs and even though the

16 former only yields shell-related chemical cues over time frames longer than our

17 experiments. These results thus suggest that shell availability is not the only, or even the

18 primary, reason marine intertidal hermit crabs aggregate at carrion sites; they also

19 aggregate to forage, thereby playing an important role as active carrion scavengers in

20 intertidal ecosystems.

22 Keywords: chemical ecology; field provisioning experiments; hermit crabs; rocky

23 intertidal; tide pools; scavengers 


\section{Introduction}

26 Tide pools within the rocky intertidal boast exceptionally high levels of

27 biodiversity as well as some of the strongest levels of physical disturbance of any habitat

28 (Denny and Gaines 2007). Ocean waves crashing on rocky shores routinely move at

29 speeds of more than $5 \mathrm{~m} / \mathrm{s}$ (Gaylord 1999), generating powerful hydrodynamic forces that

30 can dislodge even well anchored organisms (Denny et al. 1998; Gaylord et al. 2001).

31 Intertidal wave action can also shift rocks and other heavy materials, putting organisms at

32 risk of being smashed in spite of their protective shells and armored exteriors (Vermeij

33 1993). As a consequence, carrion is frequently produced in tide pools within the rocky

34 intertidal, both through abiotic forces like wave action and through biotic forces like

35 shell-crushing predators (Vermeij 1993). Many species rely on such carrion 'casualties'

36 and the trophic transfer of nutrients they provide (King et al. 2007). However, the

37 availability of fresh carrion is unpredictable (Britton and Morton 1994) and therefore the

38 most effective scavengers must be able to quickly locate and dominate new carrion

39 resources. What species show such behavioral specializations for a scavenging lifestyle in

40 tide pools?

41 Of the many organisms that inhabit tide pools, crustaceans exhibit acute

42 chemosensory abilities (reviewed in Breithaupt and Theil 2011). As such, many

43 crustaceans can quickly locate the scent of carrion and orient to this valuable food source.

44 As crustaceans, hermit crabs (Decapoda, Anomura) share these fine chemosensory

45 abilities (Gherardi and Tricarico 2011), and their mobility and abundance in tide pools

46 makes them excellent candidates as carrion scavengers (Britton and Morton 1994).

47 Intertidal hermit crabs, however, are primarily considered microphagous detritivores 
48 (Reese 1969; Kunze and Anderson 1979; Hazlett 1981; Rittschof 2007) and are thought

49 to only scavenge for carrion as a secondary foraging strategy (Schembri 1982). Yet

50 surprisingly little empirical work has actually assessed hermit crab's effectiveness as

51 carrion scavengers or compared them with other sympatric intertidal species. Indeed, as

52 Hazlett (1981, p. 1) noted on the first page of his review of hermit crab behavior, still

53 authoritative after over three decades: "Most ecological studies have focused completely

54 on the crab-shell interaction, and relatively little work has been done on the crabs as an

55 element of marine ecosystems." Consequently, relatively little is known about the feeding

56 ecology of many intertidal hermit crabs (Bertness 1981; Hazlett 1981; Elwood and Neil

57 1992; Tran 2013), so their potential role as active scavengers in intertidal ecosystems has

58 not been fully addressed.

59 Pioneering experiments by McLean (1974) and Rittschof (1980a) highlighted

60 hermit crabs' attraction to simulated predation sites involving the scent of killed

61 gastropods. An ability to quickly locate gastropod predation events may aid hermit crabs

62 in finding new shells, since many predators leave shells intact after consuming the

63 gastropod's flesh (reviewed in Table 1 of McGuire and Williams 2010). It has therefore

64 been argued (Rittschof 1980b, 1992; Rittschof et al. 1992; Mclean 1983; Gilchrist 1984;

65 Pezzuti et al. 2002; Tricarico and Gherardi 2006; Tricarico et al. 2009) that hermit crabs

66 are attracted to the scent of gastropod flesh primarily, if not exclusively, because it serves

67 as an indicator of shell availability. Critically though the attractants in gastropod flesh

68 that indicate shell availability are only released an hour or more after a gastropod is

69 smashed; or if the gastropod flesh is treated with predator proteases like trypsin, which

70 generates small peptides that serve as 'shell cues' (Rittschof 1980b). In contrast, carrion 
71 from freshly smashed gastropod that is less than $1 \mathrm{~h}$ old and has not been treated with

72 proteases (or carrion from non-gastropod sources) should only be attractive to hermit

73 crabs as food, given it does not provide shell-related cues. So hermit crabs attracted to

74 such non-shell carrion?

75 Interestingly, laboratory studies have demonstrated that despite the absence of

76 shell cues, fresh gastropod carrion as well as other types of non-gastropod carrion can

77 sometimes be attractive to hermit crabs (Tricarico et al. 2011). Additionally, both

78 laboratory and field observations have suggested that even when crabs are attracted to

79 carrion from gastropods, they may show an interest not just in entering a new shell but

80 also in consuming the flesh remaining within the shell (Laidre 2011; McGuire and

81 Williams 2010). Notably, some predators do not leave gastropod shells intact or suitable

82 for occupation by hermit crabs (Vermeij 1993), even though a by-product of their

83 predation may be strong chemical 'shell cues' indicative of gastropod death. Thus, even

84 the scent of gastropod flesh that is more than an hour old will not always be predictive of

85 newly available shells. And yet hermit crabs might still benefit from being attracted,

86 given the value of carrion itself as a protein-rich food source worth fighting over (Britton

87 and Morton 1994; Laidre 2007). Hermit crabs might therefore fulfill an important

88 ecological role within marine ecosystems if their scavenging extends beyond searching

89 for shells. Is there any evidence that hermit crabs fulfil such a generalist foraging role?

$90 \quad$ In the laboratory, hermit crabs signal and fight intensely for mussel (Laidre 2007;

91 Laidre and Elwood 2008), a carrion source that is not associated with a suitable shell

92 home for hermit crabs. And in the wild, a limited number of field experiments have

93 suggested that hermit crabs can be highly motivated for other non-gastropod carrion. 
94 Specifically, Ramsay et al. (1997) deployed an underwater video camera to film

95 scavengers that were experimentally attracted to dead fish bait dropped into the sub-tidal.

96 Only two trials were conducted, but in both trials hermit crabs (Pagurus bernhardus)

97 were the fastest scavengers to arrive at the site, forming the largest aggregations of any

98 species, and remaining at the site for extended periods to fight for and feed on the carrion.

99 Similarly, Scully (1983) reported a single trial involving a crushed mussel in the intertidal

100 and found that nearly 100 hermit crabs (Pagurus longicarpus) swiftly swarmed to and

101 dominated the site within minutes. Both these preliminary reports deserve more

102 systematic follow-ups, with a larger number of trials.

103 Here we examined the potential role of hermit crabs as scavengers based on their

104 attraction to fresh carrion that lacked any associated 'shell cues'. Our experiments tested

105 the attractive value of two types of carrion, gastropod and mussel carrion. Mussel does

106 not provide a suitable shell for hermit crabs, so when smashed it should be attractive only

107 as an eatable carrion source. Likewise, because we provided both the mussel and the

108 gastropod carrion immediately after smashing live specimens, we ensured that there were

109 no shell cues associated with the gastropod carrion. Our experiments thus revealed how

110 strongly hermit crabs were attracted to carrion that was purely indicative of food rather

111 than shells. We incorporated controls for each carrion type and structured our

112 observations to reveal the total number of crabs that aggregated (the size of their

113 'swarm') as well as the temporal dynamics over which they were attracted (how 'swiftly'

114 they arrived). Moreover, we compared hermit crabs' attraction to the carrion with that of

115 sympatric species to measure hermit crabs' relative importance as scavengers within the

116 ecosystem. Our experiments therefore allowed us to ask whether intertidal hermit crabs 
117 perform an important ecological role, acting as swarms of swift scavengers that converge

118 to feed on intertidal carrion more quickly and in greater abundance than other species.

\section{Methods}

121 Study site and species

122 We conducted our experiments in the Pacific intertidal off the coast of California,

123 an area renowned for its biodiversity (Morris et al. 1980). Prior field experiments on

124 hermit crabs' attraction to simulated predation sites have, for the most part, been

125 conducted in the Atlantic Ocean (Rittschof 1980a; Tricarico and Gherardi 2006) and the

126 Mediterranean Sea (Tricarico et al. 2009), so our study provides valuable comparative

127 data from the Pacific. Observations and experiments were carried out in the rocky

128 intertidal habitat (Figure S1) outside the Bodega Marine Laboratory, located on the

129 Bodega Marine Reserve in Sonoma County. A rich community of marine species inhabits

130 this area of the intertidal, including: (1) three species of hermit crabs (Pagurus samuelis,

131 Pagurus hirsutiusculus, and Pagurus granosimanus; Bollay 1964); (2) a variety of

132 species of shelled mollusks, with the California mussel (Mytilus californianus) being

133 especially abundant, and with the black turban snail (Chlorostoma funebrale, previously

134 classified as Tegula funebralis) being the most abundant gastropod; (3) many species of

135 brachyuran crabs (including members of the Pugettia, Scyra, Cancer, Lophopanopeus,

136 Pachygrapsus, and Hemigrapsus genera); and (4) several species of gobie (Gobiidae)

137 (Morris et al. 1980). Carrion produced in this area of the intertidal is thus potentially

138 available to many species. 
140 General experimental protocol

141 To investigate hermit crab carrion scavenging we conducted 100 experiments, 80

142 described in this section and another 20 described in the next section. For 80 experiments

143 we provisioned tide pools with either a gastropod (C. funebrale) or a mussel ( $M$.

144 californianus). Of these 80 experiments, 20 each were conducted using $(i)$ a live

145 gastropod (control), (ii) a gastropod killed by smashing, (iii) a live mussel (control), or

146 (iv) a mussel killed by smashing. Local rocks were used to smash the gastropods and

147 mussels. All experiments were conducted during daylight at low tide, spanning February

148 to July 2011. The experimental condition (gastropod or mussel, live or smashed) was

149 randomly allocated.

150 Each experiment involved the same core design and set of steps. First the

151 experimenter (either A.G. or M.L.) located a tide pool. Most tide pools at the study site

152 have lengths and widths between one and three meters. We found a flat area within the

153 tide pool that was open to observation and not obscured by seaweed. We then set down a

154 quadrat $(14.5 \times 14.5 \mathrm{~cm})$ composed of black wire. This quadrat was used to demarcate the

155 focal area immediately surrounding where the stimulus (gastropod or mussel) was

156 eventually introduced. After placing the quadrat, the experimenter moved to the edge of

157 the tide pool and observed for several minutes to confirm that hermit crabs were present

158 within the pool. If there was at least one hermit crab on two or more sides of the quadrat,

159 then the experimenter remained in position and began an experiment (Figure 1).

160 Throughout the experiment the experimenter remained stationary while observing the 161 quadrat from above. 
Each experiment lasted $20 \mathrm{~min}$, the design paralleling experiments in terrestrial

163 hermit crabs by Laidre (2010). During the first $10 \mathrm{~min}$ (from $\mathrm{t}=-10$ to $\mathrm{t}=0 \mathrm{~min}$ ) we

164 collected baseline data on the number of hermit crabs and any other macroscopic

165 scavengers (gastropods, brachyuran crabs, and gobies) that we observed in the quadrat at

166 1-min intervals. During this control period no materials had yet been placed inside the

167 quadrat, so the data indicate the general background activity within the tide pools. At the

168 end of the control period $(\mathrm{t}=0 \mathrm{~min})$, the experimenter extended his or her arm above the

169 quadrat and dropped a set of prepared materials (detailed below) into the center of the

170 quadrat. This arm movement and the materials that were dropped in typically caused

171 nearby hermit crabs to temporarily duck in their shells, but only temporarily. Usually

172 within seconds, crabs and other organisms emerged and resumed their prior behavior.

173 Once the materials had been dropped into the quadrat, initiating the experimental period,

174 we recorded the same data (on the number of crabs and other species present in the

175 quadrat) for another $10 \mathrm{~min}$ (from $\mathrm{t}=1$ to $\mathrm{t}=+10 \mathrm{~min}$ ) at 1 -min intervals. We noted the

176 exact time (to the nearest second) that an organism (hermit crab or other) first initiated

177 contact with the dropped in item. If the organism that first made contact was not a hermit

$178 \mathrm{crab}$, then we also noted when the first hermit crab subsequently made contact with the

179 item. Since it was not possible to readily differentiate the three hermit crab species from

180 overhead (and all were present in the quadrats at the end of our experiments on multiple

181 occasions), we grouped them together in our count.

182 The materials that were dropped into the quadrat (gastropod or mussel, whether

183 live or smashed) were wrapped in black rubber mesh that was tied with thin wire and

184 weighted down with a metal weight (100 g). The mesh allowed carrion chemical cues to 
185 emanate and also allowed scavengers to pick at available carrion while still keeping the

186 specimen (whether live or smashed) consolidated. The metal weight anchored the

187 materials inside the quadrat, so that attraction to the bait could be readily observed. We

188 collected the mussel or gastropod specimen immediately prior to each experiment,

189 preparing the materials to be dropped in during the 10 min control period and then

190 smashing the specimen (if it was to be killed) immediately before $\mathrm{t}=0 \mathrm{~min}$. Mussel and

191 gastropod specimens were chosen such that the raw amount of flesh they contained was

192 approximately equal: the mussels, with their elliptical shape, were chosen with lengths of

$1932-3 \mathrm{~cm}$, while the gastropods, with their more globular shape, were chosen with lengths

194 and heights of $1-2 \mathrm{~cm}$.

195 At the end of each experiment, the quadrat, the attached weight, and the

196 experimenter's hands were all washed thoroughly in seawater before beginning the next

197 experiment, thus eliminating any residual odor from the prior experiment. New mesh and

198 new wire were used for each experiment. Individual tide pools were only tested once per

199 day, and on subsequent test days we targeted our experiments in different broad sections

200 of our study site (see Figure S1) to avoid re-testing the same tide pools. In the few cases

201 where some tide pools might possibly have been re-tested, there were at least several

202 days (and up to 30 days) intervening since they were last tested - and thus the highly

203 mobile inhabitants in these pools, like hermit crabs, had almost certainly changed.

205 Extended experiments

206 An additional set of 20 extended experiments were conducted using the same core

207 design as described above, with a lengthened experimental period that lasted for 30 min 
208 after the materials were dropped into the tide pool. These experiments all used smashed

209 mussel, and were undertaken to determine if the number or composition of scavengers

210 inside the quadrat varied over longer periods.

211

212 Analyses and predictions

213 We tested the effect of each of the four conditions (gastropod smashed, gastropod live,

214 mussel smashed, and mussel live) on the number of hermit crabs and other attendants

215 attracted to the quadrat and on the speed with which contact was first made. All data

216 analyses were conducted in R (R Core Team 2012). For data that was non-normally

217 distributed, we first tried transforming the data and otherwise used non-parametric tests.

218 We predicted that if eatable, non-shell carrion is attractive to hermit crabs, then

219 the number of hermit crabs within the quadrat would significantly increase from the

220 control period to the experimental period in both the gastropod smashed and mussel

221 smashed conditions, but not in the two control conditions (gastropod live and mussel

222 live). To test this prediction we compared the final sample point during the control period

$223(\mathrm{t}=0 \mathrm{~min})$ with the final sample point during the experimental period $(\mathrm{t}=+10 \mathrm{~min})$. The

224 means for each of these sample points, across all experiments of a given condition, were

225 compared using a Wilcoxon signed rank test (a non-parametric equivalent to a paired t-

226 test, since data were not always normally distributed). We also conducted a separate

227 analysis in which we compared (1) the average number of crabs in the quadrat during the

22810 sample points in the control period $(t=-10$ to $t=-1$ min) with $(2)$ the average number

229 of crabs in the quadrat during the 10 sample points in the experimental period $(\mathrm{t}=+1$ to $\mathrm{t}$

$230=+10 \mathrm{~min})$. The ten counts made during each of these two periods were then averaged 
231 and the means across all experiments were compared with a Wilcoxon signed rank test.

232 Ultimately, we obtained similar results from both these different analyses, aside from one

233 exception. In the Results section we therefore report the one exception and otherwise

234 only detail our analyses based on comparing the final two sample points.

235 If both gastropod and mussel carrion in general is attractive to hermit crabs, then

236 we predicted there would be no significant difference between the gastropod smashed

237 condition and the mussel smashed condition, either in the number of hermit crabs that

238 accumulated in the quadrat or in the speed with which hermit crabs first arrived and

239 contacted each type of carrion. We tested this prediction by examining the number of

240 hermit crabs in the final sample point $(\mathrm{t}=+10 \mathrm{~min})$ for the gastropod smashed and

241 mussel smashed conditions and by examining when hermit crabs first touched each type

242 of carrion.

243 All the tests described above were also carried out for every species besides

244 hermit crabs that was counted inside the quadrat. We predicted that if hermit crabs fulfill

245 an important scavenging role compared to other organisms in the intertidal, then hermit

246 crabs would show a significant increase in response to carrion whereas other organisms

247 would not. We also predicted that if hermit crabs are not just scavengers but are also

248 swift scavengers, then they would consistently be the first organism to make contact with

249 the carrion after it was dropped into the quadrat.

250 Finally, to test whether the number or composition of scavengers varied over

251 longer time periods, we compared the scavengers present in the quadrat at the end of the

252 normal-length experiments $(\mathrm{t}=+10 \mathrm{~min})$ versus the end of the longer experiments $(\mathrm{t}=$

$253+30 \mathrm{~min}$ ), both of which involved smashed mussel. 
Figures in the results show the counts of hermit crabs made at each 1-min sample

255 point across the entire experiment (from $\mathrm{t}=-10$ to $\mathrm{t}=+10 \mathrm{~min}$ ), documenting the

256 temporal dynamics of hermit crabs' numbers within the quadrat.

\section{$258 \quad$ Results}

259 Increase in hermit crab numbers

260 Hermit crabs were strongly attracted to the carrion in the gastropod smashed and

261 mussel smashed conditions, with their numbers rising steeply across the experimental

262 period (Figure 2). In particular, hermit crabs increased significantly in the quadrat

263 between the end of the control period and the end of the experimental period for both

264 conditions (Wilcoxon signed-rank tests; smashed gastropod: $\mathrm{T}=3, \mathrm{~N}=20, \mathrm{p}<0.0001$;

265 smashed mussel: $\mathrm{T}=4, \mathrm{~N}=20 \mathrm{p}<0.0001$; effect sizes for both conditions were large:

266 Table 1). No such increase in the number of hermit crabs occurred for either the

267 gastropod live or the mussel live condition (Wilcoxon signed-rank test; gastropod live: T

$268=102, \mathrm{~N}=20, \mathrm{p}=0.874$; mussel live: $\mathrm{T}=75, \mathrm{~N}=20 \mathrm{p}=0.312)^{1}$. In addition to

269 accumulating in number within the quadrat, hermit crabs were also significantly more

270 likely to contact the smashed gastropod and mussel conditions compared to the live

271 gastropod and mussel conditions (Fisher's exact test: $\mathrm{p}<0.001$; Figure 3A).

273 Attraction to gastropod versus mussel

274 The smashed gastropod and mussel conditions appeared equally attractive to

275 hermit crabs: there was no difference between these conditions in the number of hermit

\footnotetext{
${ }^{1}$ In the mussel live condition, there was a significant (but minor) increase in the number of hermit crabs between the control and experimental period: this occurred only when the analysis included all sample points, rather than just the two at the end of the control and experimental period (compare Tables 1 and 2).
} 
276 crabs that accumulated at the end of the experimental period (Mann-Whitney U test; $U=$

$27719.93, \mathrm{~N}_{1}=20, \mathrm{~N}_{2}=20 \mathrm{p}=0.604$; compare Figure 2A versus 2C). Nor was there a

278 difference in the speed with which hermit crabs first made contact with either type of

279 carrion (data log transformed, t-test; $\mathrm{t}_{35}=0.1367, \mathrm{p}=0.89$; Figure 3B).

280

281 Hermit crabs versus other organisms

282 In contrast to the results for hermit crabs, no other organisms showed a significant

283 change in abundance between the control and experimental period for any of the

284 conditions (Table 1; Figures S2-S4). Moreover, hermit crabs were consistently the first

285 organism to make contact with both the gastropod and the mussel, whether it was

286 provided smashed or live: of our $\mathrm{N}=80$ experiments, in $\mathrm{N}=58$ experiments an organism

287 successfully contacted the item within 10 min of our dropping it in, and in all but one of

288 those instances the organism making first contact was a hermit crab.

290 Aggregation size over time

291 The size of hermit crabs' aggregations did not change when they were given three

292 times longer to aggregate: no significant difference existed in the number of hermit crabs

$29310 \mathrm{~min}$ after compared to 30 min after the smashed mussel was dropped-in (Mann-

294 Whitney U test: $U=32.34, p=0.395$; Figure 4). Hermit crabs thus reached peak

295 aggregation size relatively quickly in response to carrion.

\section{Discussion}


299 (Hazlett 1981). However, shells are not the only resource that matters for hermit crabs

300 (Schembri 1982; Ramsay et al. 1997; Laidre 2011; Tran 2013; Tran et al. in press). Like

301 other organisms, hermit crabs must acquire enough food to fuel growth and survival.

302 Carrion may, therefore, represent a critical food resource for hermit crabs, especially in

303 the intertidal, where high levels of abiotic and biotic disturbance frequently result in

304 organisms either being smashed by waves (Denny et al. 1998; Gaylord 1999, 2007;

305 Gaylord et al. 2001) or crushed by predators (Vermeij 1987, 1993).

306 In the present study, we simulated carrion production in the intertidal by smashing

307 shell-bearing organisms (gastropods and mussel) that live sympatrically with hermit

308 crabs. We found that hermit crabs were strongly attracted to this carrion, even though

309 neither carrion source was associated with shell cues and thus only indicated a potential

310 food resource. Our results thus suggest that marine intertidal hermit crabs are not solely

311 attracted to scents that indicate shell availability and that, at least in some populations,

312 hermit crabs are highly motivated for carrion consumption (Scully 1983; Ramsay et al.

313 1997) ${ }^{2}$. These results contrast with some other studies that have provisioned carrion to

314 hermit crabs (e.g., Rittschof 1980a, Gilchrist 1984; Bozzano and Sarda 2002), which

315 found that hermit crabs are only attracted to gastropod carrion once it begins to emanate

316 peptides that are shell cues. What could account for these divergent results?

317 Different populations of hermit crabs may experience varying degrees of food

318 versus shell limitation, with some areas having a more reliable supply of food and some

319 having a more reliable supply of shells (Hazlett 1981; Barnes and De Grave 2000).

\footnotetext{
${ }^{2}$ Similar attraction to smashed mussel and other carrion occurs in intertidal hermit crabs in Northern Ireland (Pagurus bernhardus) and in Costa Rica (Clibanarius albidigitus and Calcinus obscurus) (Laidre, personal observation).
} 
320 Spatial heterogeneity in food or shell availability could therefore account for the

321 differences between studies that have examined hermit crabs' motivation for carrion with

322 versus without shell cues. Interestingly, even within the same population, hermit crabs'

323 relative motivation for eatable carrion versus carrion that is also indicative of shells could

324 change dramatically across time due to large-scale ecological events, like red tides

325 (Prezelin 2007). Such events may kill vast numbers of gastropods, while leaving their

326 shells intact, thereby generating a temporarily surplus of shells in the hermit crab housing

327 market and increasing the importance of carrion as a source of food to fuel growth.

328 Additionally, if crabs are satiated before being offered chemical cues (e.g. Gherardi and

329 Atema 2005), then their attraction to food related cues would likely lessen. Further

330 comparative studies across hermit crabs species, as well as studies focusing on single

331 hermit crab populations during temporally dynamic ecological events, could reveal

332 interesting switch points in crabs' relative resource motivation. A fundamental predictor

333 should be which resource (shells or food) is currently most limiting in the population: at

334 sites where hermit crabs have few shells, they should be more attracted carrion associated

335 with shell cues; whereas at sites where hermit crabs have abundant shells but limited food

336 they should be attracted to carrion even if it lacks shell cues.

337 While hermit crabs aggregated quickly for carrion in our study and while these

338 aggregations persisted across time, the precise behaviors that crabs exhibited within their

339 aggregations could not be quantified under the field conditions of our experiments. We

340 did consistently observe hermit crabs feeding on both forms of carrion (gastropod and

341 mussel) by picking through the mesh and eating bits of torn flesh. However, it was

342 unclear whether crabs might have also exhibited some behaviors related to shell 
343 acquisition (e.g., by fighting or 'piggybacking' on each other's shells in anticipation of a

344 shell switch). Such behaviors are possible because even if crabs are originally attracted to

345 a site for the purpose of eating, other motivations could subsequently surface. Controlled

346 laboratory experiments (e.g., Tricarico et al. 2011) would enable greater focus on crabs'

347 fine-grained behavior within aggregations.

348 Even if hermit crabs may be motivated to eat carrion, the question remains how

349 their carrion scavenging compares with other scavenging species in the ecosystem

350 (Britton and Morton 1994; King et al. 2007; Breithaupt and Theil 2011). Our study

351 suggests that hermit crabs can be swarms of swift scavengers, performing an essential

352 carrion scavenging role in intertidal ecosystems: hermit crabs were consistently the

353 fastest to arrive at our sites, accumulated in the largest numbers, and their aggregations

354 persisted across extended time periods. These results, however, do not imply that hermit

355 crabs are necessarily the most dominant scavenger at all times. All our experiments were

356 conducted at low tide, so it is possible that at high tide other species might outcompete

357 hermit crabs for carrion. Indeed, at high tide, fish and other larger scavengers might be

358 able to arrive at carrion sites faster than hermit crabs. Additionally, hermit crab behavior

359 may differ at high tide because the influx of large predators forces some hermit crab

360 species to take refuge in protective crevices (Bertness 1981). Only by conducting

361 identical experiments at high tide, perhaps using underwater cameras to record the

362 attracted scavengers, could the generality of hermit crabs' scavenging dominance be

363 tested (though see Ramsay et al. 1997 for evidence of scavenging dominance in sub-tidal

364 hermit crabs). It is clear from studies in other areas (e.g., the sandy shores in Hong Kong:

365 Morton and Yuen 2000) that hermit crabs are not always the most dominant scavenger; 
366 other sympatric species, such as carnivorous gastropods, can sometimes outcompete

367 them. Nevertheless, at rocky intertidal sites in California, hermit crabs appear to perform

368 a generalized scavenging role that, at low tide, outstrips any other sympatric species,

369 invertebrate or vertebrate.

370

\section{Acknowledgements}

372 We thank the Bodega Marine Laboratory and the California Department of Fish

373 and Wildlife for permission to conduct this research. We are especially grateful to Jackie

374 Sones, Kitty Brown, and Eric Sanford at Bodega and to Tim Herrlinger at Berkeley for

375 their helpful advice, discussion, and logistical support. We also thank Jennifer Bates and

376 Maryann Davies for assistance with some of the final field experiments. Research was

377 supported by funding from the Miller Institute at Berkeley to M.L.

378

379

References

Barnes D, De Grave S (2000) Ecology of tropical hermit crabs at Quirimba Island, Mozambique: niche width and resource allocation. Mar Ecol Prog Ser 206:171-179. doi: $10.3354 /$ meps 206171

Bertness MD (1981) Predation, Physical Stress, and the Organization of a Tropical Rocky

391 Breithaupt T, Theil M (2011) Chemical Communication in Crustaceans. Springer, New 392

Bollay M (1964) Distribution and utilization of gastropod shells by the hermit crabs Pagurus samuelis, Pagurus granosimanus, and Pagurus hirsutiusculus at Pacific Grove California. Veliger 6 (suppl.):71-76.

Bozzano A, Sarda F (2002) Fishery discard consumption rate and scavenging activity in the northwestern Mediterranean Sea. ICES J Mar Sci 59:15-28. doi: 10.1006/jmsc. 2001.1142 York 
393

394

395

396

397

398

399

400

401

402

403

404

405

406

407

408

409

410

411

412

413

414

415

416

417

418

419

420

421

422

423

424

425

Britton JC, Morton B (1994) Marine carrion and scavengers. Oceanogr Mar Biol Annu Rev 32:369-434.

Denny M, Gaylord B, Helmuth B, Daniel T (1998) The menace of momentum : Dynamic forces on flexible organisms. Limnol Oceanogr 43:955-968.

Denny MW, Gaines SD (2007) Encyclopedia of Tidepools and Rocky Shores. University of California Press, Berkeley

Elwood R, Neil S (1992) Assessments and Decisions: A study of information gathering by hermit crabs. Chapman \& Hall, London

Gaylord B (1999) Detailing agents of physical disturbance: wave-induced velocities and accelerations on a rocky shore. J Exp Mar Bio Ecol 239:85-124. doi: 10.1016/S0022-0981(99)00031-3

Gaylord B, Hale BB, Denny MW (2001) Consequences of transient fluid forces for compliant benthic organisms. J Exp Biol 204:1347-60.

Gherardi F, Atema J (2005) Effects of chemical context on shell investigation behavior in hermit crabs. J Exp Mar Bio Ecol 320:1-7. doi: 10.1016/j.jembe.2004.12.022

Gherardi F, Tricarico E (2011) Chemical Ecology and Social Behaviour of Anomura. In: Breithaupt T, Theil M (eds) Chem. Commun. Crustac. Springer, New York, pp 297312

Gilchrist S (1984) Specificity of hermit crab attraction to gastropod predation sites. J Chem Ecol 10:569-582.

Hazlett B (1981) The Behavioural Ecology of Hermit Crabs. Annu Rev Ecol Syst 12:122.

King N, Bailey D, Priede I (2007) Role of scavengers in marine ecosystems. Mar Ecol Prog Ser 350:175-178. doi: 10.3354/meps07186

Kunze J, Anderson DT (1979) Functional Morphology of the Mouthparts and Gastric Mill in the Hermit Crabs Clibanarius taeniatus (Milne Edwards), Clibanarius virescens (Krauss), Paguristes squamosus (McCulloch) and Dardanus setifer (MileEdwards) (Anomura: Paguridae). Austrailian J Mar Freshw Res 30:683-722.

Laidre ME (2007) Vulnerability and reliable signaling in conflicts between hermit crabs. Behav Ecol 18:736-741. doi: 10.1093/beheco/arm040

Laidre ME (2010) How rugged individualists enable one another to find food and shelter: field experiments with tropical hermit crabs. Proc Biol Sci 277:1361-9. doi: $10.1098 / \mathrm{rspb} .2009 .1580$ 
426

427

428

429

430

431

432

433

434

435

436

437

438

439

440

441

442

443

444

445

446

447

448

449

450

451

452

453

454

455

456

457

458

459

Laidre ME (2011) Ecological relations between hermit crabs and their shell-supplying gastropods: Constrained consumers. J Exp Mar Bio Ecol 397:65-70. doi: 10.1016/j.jembe.2010.10.024

Laidre ME, Elwood RW (2008) Motivation matters: cheliped extension displays in the hermit crab, Pagurus bernhardus, are honest signals of hunger. Anim Behav 75:2041-2047.

McGuire BM, Williams JD (2010) Utilization of partially predated snail shells by the hermit crab Pagurus longicarpus Say, 1817. Mar Biol 157:2129-2142. doi: $10.1007 / \mathrm{s} 00227-010-1478-5$

McLean RB (1974) Direct shell acquisition by hermit crabs from gastropods. Experientia 30:206-208. doi: 10.1007/BF01927738

Mclean R (1983) Gastropod shells: a dynamic resource that helps shape benthic community structure. J Exp Mar Bio Ecol 69:151-174.

Morris RH, Abbott DP, Haderlie EC (1980) Intertidal Invertebrates of California. Stanford University Press, Stanford, CA

Morton B, Yuen W (2000) The feeding behaviour and competition for carrion between two sympatric scavengers on a sandy shore in Hong Kong: the gastropod, Nassarius festivus (Powys) and the hermit crab, Diogenes edwardsii (De Haan). J Exp Mar Bio Ecol 246:1-29.

Pezzuti J, Turra A, Leite F (2002) Hermit crab (Decapoda, Anomura) attraction to dead gastropod baits in a infralittoral algae bank. Brazilian Arch Biol Technol 45:245250.

Prezelin BB (2007) Algal Blooms. In: Denny MW, Gaines SD (eds) Encycl. Tidepools Rocky Shores. University of California Press, London, pp 30-33

Ramsay K, Kaiser MJ, Hughes RN. 1997. A Field Study of Intraspecific Competition for Food in Hermit Crabs (Pagurus bernhardus). Estuarine, Coastal and Shelf Science 44: 213-220.

Reese ES (1969) Behavioral Adaptations of Intertidal Hermit Grabs. Am Zool 9:343355.

Rittschof D (1980a) Chemical attraction of hermit crabs and other attendants to simulated gastropod predation sites. J Chem Ecol 6:103-118. doi: 10.1007/BF00987531

Rittschof D (1980b) Enzymatic production of small molecules attracting hermit crabs to simulated gastropod predation sites. J Chem Ecol 6:665-675. doi: 10.1007/BF00987677 
460 Rittschof D (1992) Chemosensation in the daily lives of crabs. Amer Zool 32:363-369.

461 Rittschof D (2007) Hermit Crabs. Encycl Tidepools Rocky Shores 273-274.

462 Rittschof D, Tsai DW, Massey PG, et al. (1992) Chemical mediation of behavior in 463 hermit crabs: Alarm and aggregation cues. J Chem Ecol 18:959-84. doi:

$464 \quad 10.1007 / \mathrm{BF} 00980056$

465 Schembri PJ (1982) Feeding behaviour of fifteen species of hermit crabs (Crustacea:

466 Decapoda: Anomura) from the Otago region, southeastern New Zealand. J Nat Hist $467 \quad$ 16:859-878. doi: $10.1080 / 00222938200770691$

468 Scully EP (1983) The behavioral ecology of competition and resource utilization among 469 hermit crabs. In: Rebach S, Dunham DW (editors) Studies in adaptation: the 470 behaviour of higher crustacea. New York: Wiley and Sons.

Team RC (2012) R: A language and environment for statistical computing.

Tran MV (2013) Divergent reactions to olfactory foraging cues between two ecologically similar, sympatric hermit crab species. J Crustac Biol 33:512-518. doi: 10.1163/1937240X-00002154

Tran MV, O’Grady M, Colborn J, Van Ness K, Hill W (2014). Aggression and food resource competition between sympatric hermit crab species. PLoS ONE 9(3): e91823.

Tricarico E, Bertocchi S, Brusconi S, et al. (2009) Shell recruitment in the Mediterranean hermit crab Clibanarius erythropus. J Exp Mar Bio Ecol 381:42-46. doi: 10.1016/j.jembe.2009.09.001

Tricarico E, Breithaupt T, Gherardi F (2011) Interpreting odours in hermit crabs: A comparative study. Estuar Coast Shelf Sci 91:211-215. doi: 10.1016/j.ecss.2010.10.039

484 Tricarico E, Gherardi F (2006) Shell acquisition by hermit crabs : which tactic is more 485 efficient? Behav Ecol Sociobiol 60:492-500. doi: 10.1007/S00265-006-0191-3

486 Vermeij G (1987) Evolution and escalation: an ecological history of life, 1st ed. Princeton University Press, Princeton, NJ 
Table 1 Wilcoxon signed rank tests comparing the number of each organism at the end of the control period $(t=0$ min) versus the end of the experimental period $(t=+10 \mathrm{~min})$.

\section{Experimental condition}

\begin{tabular}{ccccc} 
& $\begin{array}{c}\text { Gastropod } \\
\text { smashed }\end{array}$ & $\begin{array}{c}\text { Gastropod } \\
\text { live }\end{array}$ & $\begin{array}{c}\text { Mussel } \\
\text { smashed }\end{array}$ & $\begin{array}{c}\text { Mussel } \\
\text { Live }\end{array}$ \\
\hline $\begin{array}{c}\text { Hermit } \\
\text { Crabs }\end{array}$ & $\begin{array}{c}\mathbf{T}=\mathbf{3}, \\
\mathbf{p}<\mathbf{0 . 0 0 0 1}, \\
\mathbf{E S}=\mathbf{0 . 9 4 7}\end{array}$ & $\begin{array}{c}\mathrm{T}=102, \\
\mathrm{p}=0.874\end{array}$ & $\begin{array}{c}\mathbf{T}=\mathbf{4}, \\
\mathbf{p}<\mathbf{0 . 0 0 0 1},\end{array}$ & $\mathrm{T}=75$, \\
& & $\mathbf{E S}=\mathbf{0 . 9 4 4}$ & \\
Gastropods & $\mathrm{T}=87$, & $\mathrm{T}=96$, & $\mathrm{T}=77$, \\
& $\mathrm{p}=0.497$ & $\mathrm{p}=0.604$ & $\mathrm{p}=0.386$ & $\mathrm{~T}=0.574$ \\
Brachyuran & $\mathrm{T}=104$, & $\mathrm{T}=105$, & $\mathrm{T}=96$, & \\
crabs & $\mathrm{p}=0.510$ & $\mathrm{p}=0.492$ & $\mathrm{p}=0.514$ & $\mathrm{~T}=96$, \\
& & & & \\
Gobies & $\mathrm{T}=105$, & $\mathrm{T}=86$, & $\mathrm{T}=86$, & $\mathrm{T}=96$, \\
& $\mathrm{p}=0.566$ & $\mathrm{p}=0.465$ & $\mathrm{p}=0.500$ & $\mathrm{p}=0.559$ \\
\hline
\end{tabular}

$\mathrm{N}=20$ for each condition. To break ties and deal with zeroes in the data, we randomly altered counts by 0.001 in either direction. This process was repeated 1000 times and the average $\mathrm{V}$ statistic and $\mathrm{p}$ value reported. Effect sizes are listed where significant effects occurred. 
Table 2 Wilcoxon signed rank tests comparing mean abundance across the entire control period $(\mathrm{t}=-10$ to $-1 \mathrm{~min})$ versus the entire experimental period $(\mathrm{t}=+1$ to $+10 \mathrm{~min})$.

\section{Experimental condition}

\begin{tabular}{ccccc} 
& $\begin{array}{c}\text { Gastropod } \\
\text { smashed }\end{array}$ & $\begin{array}{c}\text { Gastropod } \\
\text { live }\end{array}$ & $\begin{array}{c}\text { Mussel } \\
\text { smashed }\end{array}$ & $\begin{array}{c}\text { Mussel } \\
\text { Live }\end{array}$ \\
\hline $\begin{array}{c}\text { Hermit } \\
\text { Crabs }\end{array}$ & $\begin{array}{c}\mathbf{T}=\mathbf{7}, \\
\mathbf{p}<\mathbf{0 . 0 0 0 1}, \\
\mathbf{E S}=\mathbf{0 . 8 8 7}\end{array}$ & $\begin{array}{c}\mathrm{T}=79, \\
\mathrm{p}=0.340\end{array}$ & $\begin{array}{c}\mathbf{T}=\mathbf{3}, \\
\mathbf{p}<\mathbf{0 . 0 0 0 1},\end{array}$ & $\begin{array}{c}\mathbf{T}=\mathbf{4 7}, \\
\mathbf{p}=\mathbf{0 . 0 3 0}, \\
\mathbf{E S}=\mathbf{0 . 4 2}\end{array}$ \\
Gastropods & $\mathrm{T}=70$, & $\mathrm{T}=\mathbf{0 . 9 7 0}$ & $\mathbf{}$ \\
& $\mathrm{p}=0.286$ & $\mathrm{p}=0.621$ & $\mathrm{p}=0.285$ & $\mathrm{p}=0.759$ \\
Brachyuran & $\mathrm{T}=95$, & $\mathrm{T}=104$, & $\mathrm{T}=91$, & \\
crabs & $\mathrm{p}=0.514$ & $\mathrm{p}=0.522$ & $\mathrm{p}=0.499$ & $\mathrm{~T}=103$, \\
& & & & $\mathrm{p}=0.512$ \\
Gobies & $\mathrm{T}=93$, & $\mathrm{T}=79$, & $\mathrm{T}=88$, & $\mathrm{T}=88$, \\
& $\mathrm{p}=0.582$ & $\mathrm{p}=0.391$ & $\mathrm{p}=0.488$ & $\mathrm{p}=0.514$ \\
& & & &
\end{tabular}

$\mathrm{N}=20$ for each condition. To break ties and deal with zeroes in the data, we randomly altered counts by adding small amounts of noise (around 0.001) in either direction. This process was repeated 1000 times and the average V statistic and $\mathrm{p}$ value reported. Effect sizes are listed where significant effects occurred. 


\section{Figure legends}

Figure 1. (1) Conditions necessary for experiment to begin, with timeline below showing 10-min control period and (2) Time at which experimental stimulus was dropped in (at $\mathrm{t}$ $=0 \mathrm{~min}$ ), with timeline below showing 10 -min experimental period. Icons represent: (a) experimenter, (b) tide pool, (c) quadrat, (d) hermit crab, (e) mesh with experimental item, and (f) weight.

Figure 2. Number $($ Mean $+\mathrm{SE})$ of hermit crabs present within the quadrat during each minute of the experiment. At $\mathrm{t}=0 \mathrm{~min}$ the experimental stimulus was dropped into the tide pool. $\mathrm{N}=20$ trials for each condition: (a) gastropods that were smashed, (b) gastropods that were live, (c) mussels that were smashed, and (d) mussels that were live.

Figure 3. (a) Proportion of trials in which hermit crabs contacted the experimental stimulus $(\mathrm{N}=20$ trials for each condition). (b) Time (Mean $+\mathrm{SE})$ till hermit crabs contacted the experimental stimulus (calculated from when the stimulus was dropped into the tide pool at $\mathrm{t}=0 \mathrm{~min}$ ). Note that since the stimulus was not contacted in every experiment, sample sizes differed across conditions (listed below each bar).

Figure 4. Number (Mean + SE) of hermit crabs that accumulated at 10 min versus 30 min after the mussel smashed condition.

\section{Electronic Supplementary Material}

Figure S1. Google Earth image of the intertidal study site outside the Bodega Marine Laboratory, with the site divided into four main stretches, each of which contained 20-30 tide pools.

Figure S2. Number (Mean $+\mathrm{SE}$ ) of gastropods present within the quadrat during each minute of the experiment. (See Figure 2 for details; scale of y-axis same as Figure 2).

Figure S3. Number $($ Mean $+\mathrm{SE})$ of brachyuran crabs present within the quadrat during each minute of the experiment. (See Figure 2 for details; scale of y-axis same as Figure 2).

Figure S4. Number (Mean + SE) of gobies present within the quadrat during each minute of the experiment. (See Figure 2 for details; scale of y-axis same as Figure 2). 